\title{
Some critical reflections on the hiddenness argument
}

\author{
Imran Aijaz • Markus Weidler
}

Received: 9 May 2006 / Accepted: 9 June 2006 /

Published online: 1 February 2007

(C) Springer Science+Business Media B.V. 2007

\begin{abstract}
J.L. Schellenberg's Argument from Divine Hiddenness maintains that if a perfectly loving God exists, then there is no non-resistant non-belief. Given that such nonbelief exists, however, it follows that there is no perfectly loving God. To support the conditional claim, Schellenberg presents conceptual and analogical considerations, which we subject to critical scrutiny. We also evaluate Schellenberg's claim that the belief that God exists is logically necessary for entering into a relationship with the Divine. Finally, we turn to possible variants of Schellenberg's case, and argue that the modifications necessary to accommodate our criticismas leave those variants with much less of a sting than originally suggested by his provocative formulation.
\end{abstract}

Keywords Schellenberg · Vanstone - Divine hiddenness - Loving God · Belief . Nonbelief $\cdot$ Accommodationist strategy

\section{Introduction}

In a recent, sustained defence of the now well-known 'Argument from Divine Hiddenness', J.L. Schellenberg concludes that his argument is "very much alive and

I. Aijaz $\cdot$ M. Weidler $(\bowtie)$

Philosophy Department, University of Auckland,

Private Bag 92019, Auckland, New Zealand

e-mail: m.weidler@auckland.ac.nz

I. Aijaz

e-mail:imran.aijaz@xtra.co.nz 
kicking". ${ }^{1}$ According to the hiddenness argument, broadly construed, the existence of a perfectly loving God entails (or, at the very least, strongly suggests) the absence of non-resistant nonbelief (of which 'reasonable' or 'inculpable' nonbelief is a species). ${ }^{2}$ Given, however, the fairly uncontroversial fact that there is non-resistant nonbelief in our world - a state of affairs that can also described by saying 'God is hidden'-one can infer the non-existence of a perfectly loving God. ${ }^{3}$

\section{Our approach}

Now, Schellenberg's argument has been criticised by several authors. ${ }^{4}$ In his response to the critics, Schellenberg divides the criticisms levelled against his argument into (1) irrelevant criticisms and (2) relevant criticisms which can be answered by what he calls the 'accommodationist strategy'. The irrelevant criticisms will not concern us here (we are in broad agreement with Schellenberg that the criticisms he classifies as irrelevant are indeed so). Most of the relevant criticisms of the hiddenness argument grant the existence of non-resistant nonbelief and focus their attention on questioning the alleged entailment (or strong suggestion) between the existence of a perfectly loving God and the absence of non-resistant nonbelief. They do this by trying to proffer a reason (which is usually connected to the existence of some greater good) for the sake of which God does not bring about a state of affairs in our world where there is a complete absence of non-resistant nonbelief. For instance, it has been claimed that God might permit the existence of non-resistant nonbelief in our world to procure the good of humans freely choosing to enter into a loving relationship with God. This would be in contrast to a world where (it is claimed) our autonomy would be coerced into submission if God had provided such strong evidence of His existence so as to banish the possibility of non-resistant nonbelief. ${ }^{6}$

By way of defending the hiddenness argument against such criticisms that try to suggest a reason for God being hidden, Schellenberg utilises the accommodationist strategy. As he explains,

$[\mathrm{T}]$ he critic must ... concede that any reason God finds appealing as a reason for remaining withdrawn from human beings must be one whose dominant concern cannot be met within the framework of divine-human interaction ... (2005b, p. 288)

\footnotetext{
1 See Schellenberg (2005a,b). The quote is taken from the abstract of Schellenberg (2005b).

2 In the original presentation of the hiddenness argument in Schellenberg (1993), he casts the argument in terms of reasonable or inculpable non-belief. To see some of the recent modifications to his original hiddenness argument, see Schellenberg's 'The Problem of Hiddenness and the Problem of Evil' (unpublished conference paper, 2004).

3 The phrase 'God is hidden' can refer to a number of different things. Schellenberg uses it specifically to refer to the obscurity of God's existence. See Divine Hiddenness, pp. 4-6.

4 See the essays in Howard-Snyder and Moser (2002).

5 See Schellenberg (2005a,b). The 'accommodationist strategy' is described in the latter of these two articles, pp. 288ff.

6 John Hick is one figure who is typically associated with such a view. For a critical discussion of Hick's ideas, see Divine Hiddenness, Ch. 5.
} 
Thus we have two contrasting scenarios:

The choice we face here is basically between (1) a picture in which the selfrevelation of God is basic - God's existence is beyond reasonable non-belief - and God withdraws if and when such withdrawal is needed to facilitate hiddenness-related goods but without ever removing the possibility of relationship with God; and (2) a picture in which withdrawal is basic - God's existence is not beyond reasonable non-belief - and God is selectively revealed to some individuals or to none at all (while allowing many to think that God is revealed to them). (2005b, p. 300)

Given what we know about God's love and nature, Schellenberg maintains that (1) is the "more intellectually attractive picture". (2005b, 9. 300)

Now all of this is well and good. There are irrelevant criticisms of the hiddenness argument, and there are those that can be responded to by utilising the accommodationist strategy. Moreover, it would seem that these two categories exhaust the sorts of criticisms that have been put forward against the hiddenness argument to date. For having dismissed the irrelevant criticisms, and turning to those that are relevant, Schellenberg maintains that "all of these criticisms, as it turns out, succumb to the very same general strategy of response ... the accommodationist strategy". 7 Although Schellenberg's two categories might exhaust the sorts of objections raised against the hiddenness argument thus far, it should be clear that they do not exhaust the list of candidate defeaters to the argument. This is an important point because a theistic respondent to the hiddenness argument need not think that a relevant objection against it has to provide a plausible reason for God's hiddenness. There is no need for a theist to unnecessarily burden herself with this difficult job, for it requires coming up with an offsetting or outweighing good ${ }^{8}$ for the sake of which God permits non-resistant nonbelief and showing that this particular good is one which cannot be brought about along the lines of the considerations given in Schellenberg's accommodationist strategy.

To see this, consider a third category of objections to the hiddenness argumentrelevant objections that do not attempt to provide a reason for God's hiddenness (and therefore are not susceptible to a response which appeals to the accommodationist strategy) but which simply question the supposed entailment (or strong suggestion) between the existence of a perfectly loving God and the absence of non-resistant nonbelief. Of course, it is true that by providing a reason for God's hiddenness one is ipso facto questioning the entailment between the existence of a perfectly loving God and the absence of non-resistant nonbelief. The converse does not apply, however; the entailment can be questioned without providing a reason for divine hiddenness. Here, it might be helpful to think of the category of objections that provide a reason for God's hiddenness as a subset of the category of objections that question the entailment between the existence of a perfectly loving God and the absence of non-resistant nonbelief. Thus, providing a reason for hiddenness is sufficient to question the entailment, but it is not necessary.

In our paper, we shall critically evaluate what we take to be the latest rendition of the hiddenness argument, by focusing on its claims about what one can rightly expect from God.

Schellenberg makes two fundamental claims about our expectations concerning the divine. The first claim about expectations is the supposed entailment (or strong

\footnotetext{
7 Schellenberg (2005b, p. 287). Emphasis ours.

8 See Schellenberg's discussion in Divine Hiddenness, Ch. 4.
} 
suggestion) between the existence of a perfectly loving God and the absence of nonresistant nonbelief. According to Schellenberg, conceptual and analogical reflection on the concept of divine love shows that, if there is a perfectly loving God, all creatures capable of explicit and positively meaningful relationship with God who haven't freely shut themselves off from Him are in a position to participate in such a relationship. And because "God, in willing a certain state, necessarily wills all of its conditions", (2005a, p. 203) Schellenberg argues that all creatures capable of explicit and positively meaningful relationship with God who haven't freely shut themselves off from Him believe that God exists. This is because the belief that God exists is a necessary condition for being in a position to exercise one's capacity for relationship with God (Ibid.). We shall argue that both the conceptual and analogical considerations given by Schellenberg fail to adequately support the entailment (or strong suggestion) between God's perfect love and the absence of non-resistant nonbelief. If, therefore, there can be reasonable doubt about whether God will bring about this particular state of affairs, this doubt will also extend to the existence of the requisite conditions of that state of affairs (i.e. the belief that God exists).

The second claim about expectations from God that the hiddenness argument refers to is the possession of the belief that God exists by all creatures capable of a relationship with God who have not freely shut themselves off from God (the availability of such belief follows from considerations about what to expect from God - the first claim). This is perhaps the most important claim of the hiddenness argument, for, as Schellenberg notes, "it is the facilitation of belief that is central to the argument". ${ }^{9} \mathrm{We}$ shall argue that Schellenberg's claim here is false. Belief is not a necessary condition to be in a position to exercise one's capacity for relationship with God.

These two claims about what to expect from God form the core of the hiddenness argument. Given that we have reason to question the first (in the form of an undercutting defeater) and to plainly reject the second (in the form of a rebutting defeater), ${ }^{10}$ Schellenberg's hiddenness argument is therefore unsuccessful. This does not mean, however, that other formulations cannot be given. Indeed, to the contrary, as Schellenberg (2002) writes, "the argument from divine hiddenness, as I have developed it, is only one among several arguments focusing on the hiddenness of God's existence". After showing why the hiddenness argument does not succeed, we shall conclude with some ruminations over variants of the argument.

Before evaluating the hiddenness argument, however, it is necessary to sharpen our focus by understanding what, exactly, the argument amounts to.

\section{Framing the argument}

Since Schellenberg's hiddenness argument was first presented in his important and challenging book, Divine Hiddenness and Human Reason, it has undergone a number of revisions. What follows is the latest form of the argument: ${ }^{11}$

\footnotetext{
9 Schellenberg, 'The Problem of Hiddenness and The Problem of Evil', p. 4, footnote 4.

10 Here we are referring to John Pollock's well-known distinction between 'undercutting' and 'rebutting' defeaters (see Pollock 1986, pp. 38-39).

11 We are grateful to J.L. Schellenberg for helping us in formulating a presentation of his argument in standard form (personal correspondence, 6th September, 2005). 
P1. If there is a perfectly loving God, all creatures capable of explicit and positively meaningful relationship with God who have not freely shut themselves off from God are in a position to participate in such a relationship - i.e. able to do so just by trying.

$\mathrm{P} 2$. No one can be in a position to participate in such a relationship without believing that God exists.

C1. If there is a perfectly loving God, all creatures capable of explicit and positively meaningful relationship with God who have not freely shut themselves off from God believe that God exists (from P1 and P2).

P3. It is not the case that all creatures capable of explicit and positively meaningful relationship with God who have not freely shut themselves off from God believe that God exists: there is non-resistant nonbelief; 'God is hidden'.

$\mathrm{C} 2$. It is not the case that there is a perfectly loving God (from C1 and P3).

$\mathrm{P} 4$. If God exists, God is perfectly loving.

C3. It is not the case that God exists (from C2 and P4).

The first move made by the hiddenness argument, by way of its initial sub-argument, is to argue that, if there is a perfectly loving God, then His existence entails a certain fact, viz., that all creatures capable of explicit and positively meaningful relationship with God who have not freely shut themselves off from Him are in a position to participate in such a relationship (P1). Since the belief that God exists is a necessary condition for being in such a position (P2), it follows that, if there is a perfectly loving God, all creatures capable of explicit and positively meaningful relationship with God who have not freely shut themselves off from God believe that God exists (C1). This initial sub-argument is a crucial preliminary in the hiddenness argument, for it describes a state of affairs that one would expect to obtain given the existence of a perfectly loving God (this state of affairs is then denied in the second sub-argument to arrive at C2 through modus tollens). In the words of Daniel Howard-Snyder and Paul K. Moser, "the argument from divine hiddenness is rooted in our expectations regarding God, specifically how a perfectly loving being would reveal Himself". ${ }^{12}$ We will call this first sub-argument in the overall hiddenness argument the 'expectations' sub-argument.

The conclusion of the expectations sub-argument is that, if there is a perfectly loving God, all creatures capable of explicit and positively meaningful relationship with God who have not freely shut themselves off from God believe that He exists (C1). In other words, the existence of a perfectly loving God entails the absence of non-resistant nonbelief. The consequent of the conditional given in $\mathrm{C} 1$ is then denied in P3 - there is non-resistant nonbelief (God is 'hidden') - resulting in a valid inference (from the conjunction of $\mathrm{C} 1$ and $\mathrm{P} 3$ ) to the conclusion that there is no perfectly loving God (C2). Since it is in this particular sub-argument that the state of affairs describing non-resistant nonbelief, or divine hiddenness, is expressed, we will call this second sub-argument the 'hiddenness' sub-argument.

The first two sub-arguments bring us to the conclusion that there is no perfectly loving God (C2). But if God exists, God is perfectly loving (P4). The conjunction of $\mathrm{C} 2$ and P4 finally gives us the main conclusion that God does not exist (C3). Since this sub-argument yields the explicitly atheistic conclusion of the overall hiddenness argument, we will call the third sub-argument the 'atheistic' sub-argument.

Taking all three sub-arguments together-the expectations, hiddenness and atheistic sub-arguments - gives us Schellenberg's (overall) hiddenness argument for atheism.

12 Howard-Snyder and Moser (2002). Emphasis ours. 
It is the expectations sub-argument that we will focus our attention on in critically evaluating Schellenberg's hiddenness argument.

\section{The expectations sub-argument}

\subsection{Schellenberg's conceptual and analogical arguments considered}

\subsubsection{Critiquing Schellenberg's conceptual argument}

The first premise of the expectations sub-argument states:

P1. If there is a perfectly loving God, all creatures capable of explicit and positively meaningful relationship with God who have not freely shut themselves off from God are in a position to participate in such a relationship - i.e. able to do so just by trying.

Before raising the question of what reason or reasons there are for thinking that $\mathrm{P} 1$ is true, it will be useful to point out that P1 appears to assume the truth of a prior (suppressed) premise in the argument, viz., this:

$\mathrm{P} 1^{\prime}$. A perfectly loving God would seek explicit and positively meaningful relationship with all creatures who are capable of it and who have not freely shut themselves off from God.

It is only by assuming that a perfectly loving God would seek an explicit and positively meaningful relationship (and by making a further assumption-one which we may grant for now - that God is capable of doing so) with all of us who are capable of it and haven't freely shut ourselves off from God, do we arrive at P1. Hence, one would need to argue for the plausibility of $\mathrm{P} 1^{\prime}$, so that the rational acceptability of $\mathrm{P} 1^{\prime}$ would then 'transfer' over to P1.

Interestingly, however, Schellenberg thinks that this is not required because he maintains that $\mathrm{P} 1$ and $\mathrm{P} 1$ ' "are in fact logically equivalent". ${ }^{13}$ In an important and revealing passage in his recent defence of the hiddenness argument, he explains,

[W]e can plausibly take ... claims as to what we would find if there were a perfectly loving God to be not just true but necessarily true. The reasoning developed in support of the idea that God would facilitate relationship ... seems applicable to any possible world containing human beings created by God - it strongly suggests that the conditionals in question reflect part of the very meaning of 'God unsurpassably loves human beings'. Hence that reasoning may be regarded as providing for those propositions a familiar sort of (defeasible) a priori justification. ${ }^{14}$

In this passage, Schellenberg mentions three salient features of the initial conditional premise of the hiddenness argument, P1. Firstly, it is part of the very meaning of 'God is perfectly loving' that God would seek an explicit and positively meaningful relationship with those who are capable of it and who have not freely shut themselves off

\footnotetext{
13 Schellenberg, personal correspondence (11th September, 2005).

14 Schellenberg (2005a, p. 204). Italics ours.

铂 Springer
} 
from God. He writes, "there seems plenty of reason to take the conditional premise in question [i.e. P1], when properly understood, as expressing a conceptual truth about divine love" (2005a, p.213). And again, "the proper explication of 'God loves human beings' must include the proposition 'God seeks to be personally related to us"'. ${ }^{15}$ If this is true, then $\mathrm{P} 1$ and $\mathrm{P} 1^{\prime}$ are indeed logically equivalent, and so we can bypass the latter and get straight to the question of whether P1 is true. Not only is P1 conceptually true, but, secondly, it is also necessarily true, according to Schellenberg. Thirdly, we are rationally entitled in holding $\mathrm{P} 1$ to be true based on a priori considerations.

The relationship between the notions of conceptuality (or analyticity), necessity and apriorism is difficult to determine, ${ }^{16}$ and Schellenberg does not make it entirely clear how he views the relationship between them. It would appear that Schellenberg is suggesting that a conceptually true proposition is known a priori and is also necessarily true. ${ }^{17}$ We will not take issue with this suggestion here, but will assume that this is the case for the sake of argument. An application of these three notions to the discussion surrounding the truth of P1 would mean that, once we properly understand what it means to say that God is loving, we will 'see' that God seeks an explicit and positively meaningful relationship with all creatures who are capable of it and who have not freely shut themselves off from God. ${ }^{18}$ And, furthermore, we will also recognise $\mathrm{P} 1$ as an a priori truth, and a necessary truth at that. Suppose, then, that this is correct. Is P1 a conceptual truth?

Unfortunately, despite his considerable discussion on the topic of love, there is very little in Schellenberg's work in support of the claim that the initial conditional premise in the argument, P1, is a conceptual truth. As a matter of fact, it appears that Schellenberg's 'conceptual analysis' of divine love collapses into another, distinct strategy he uses to support P1-using human love as an analogue for divine love (it seems that, in his work, Schellenberg wants to keep the conceptual and analogical analysis distinct but mutually complementary). ${ }^{19}$ Here are some of the relevant passages in which Schellenberg muses over the concept of divine love:

It may be observed that situations of human interactions and discussions of human interaction are the contexts in which such concepts as those of 'closeness', 'care', and 'love' are used and acquire their meanings. Thus, in forming our conception of divine love, we can do no better than to make use of what we know belongs to the best in human love. (2005a, pp. 202-203)

\footnotetext{
15 Schellenberg, Divine Hiddenness, p. 23. Emphasis ours.

16 For a good discussion of these notions, see Moser (1987).

17 This is how the relationship between conceptuality, a priorism and necessity is usually depicted. See, for example, Swinburne (1987).

18 In saying that we will 'see' that God will seek an explicit and positively meaningful relationship if we properly understand what it means to say that God is perfectly loving, we do not mean to suggest that it will be obvious for all to see. As Schellenberg explains, "not all necessary truths may be expected to stare us in the face (there are plenty of examples of nonobvious necessary truths in philosophy!) And when we are able to identify ... sociological or other causes that may prevent candidates for necessary truth from appearing obvious, their lack of this property of being obvious to everyone is obviously no evidence that they are not necessary" (Schellenberg, 2002, p. 46). The point made here is a fair one. The mere fact that a certain proposition doesn't strike us as a necessary truth in any obvious way does not mean that it is not necessarily true. Of course. But a person who claims that a certain proposition is necessarily true has all the more reason to explain why the proposition in question is necessarily true if the proposition's (alleged) necessity doesn't seem obvious to us!

19 See, for example, Schellenberg (2004).
} 
[W]hat gives our justification prima facie status is basically that its reasoning instantiates an intuitively plausible and widely accepted way of determining the meaning of divine attributes - namely, extrapolation from mundane examples of relevant properties ... [W] hat we know of how these terms [such as 'divine knowledge' and 'divine goodness'] are used in human contexts provides a prima facie good reason for believing that talk of God is to be understood in the same way. (2002, pp. 45-46)

In examining [the] concept [of divine love], [we must] develop our understanding of it ... by reference to what is best in human love. (2004, p. 39)

$[\mathrm{R}]$ eflection on the concept of divine love shows that a perfectly loving God would necessarily seek personal relationship with all individuals belonging to [the category of non-resisting nonbelievers] ... In defense of ... [this claim], we may point out that the seeking of personal relationship is an essential part of the best human love ... Something similar must apply to God's love for us. (2004, p. 40)

So, according to Schellenberg, we form our conception of divine love with reference to human love, by extrapolating from the concept of human love. But it is obvious that we form our understanding of human love through our observations in the actual world. If this is correct, as it surely is, then to state that $\mathrm{P} 1$ of the hiddenness argument is necessarily true seems too bold a claim. It is too bold for the simple reason that we have no reason to suppose that our considerations over human love will hold in every possible world containing human beings. Is it really true that all possible worlds containing loving human beings will see them seeking personal (or explicit and positively meaningful) relationships $?^{20}$ Maybe. However, one cannot simply assume that this will be the case; good reasons need to be given.

Schellenberg gives a two-fold response to this criticism of ours against his claim that $\mathrm{P} 1$ is a conceptual truth. He argues that (1) a proper understanding of human love means that we are talking about something that is conceptual and necessarily true, and so holds in all (relevant) possible worlds. And, in any case says Schellenberg, (2) it is our understanding of not just any human love but rather the best human love that is pertinent and so brings in normative considerations that are likewise conceptual and necessarily true. ${ }^{21}$

It should be clear that (1) is a necessary condition for (2) once we see that, for Schellenberg, to 'understand' something is to grasp the essence of it (for how else could merely understanding human love allow us to infer a relevant truth that is conceptually and necessarily true?). Now, if it turns out that we cannot be sure what the essence of human love is, or, in other words, if we cannot be sure whether our insight into human love is complete, then we cannot be sure whether what we take to be the best of human love is a conceptual truth that is necessarily true. This is precisely the point we wish to make against Schellenberg's claim here. Can we regard our understanding of human love as a conceptual truth? The inference to a positive answer can seem deceptively swift due to a possible equivocation on what it means to have

\footnotetext{
20 In his early formulations of the hiddenness argument, Schellenberg maintains that a conceptual analysis of divine love reveals that God seeks a 'personal' relationship. In later formulations this is changed to an 'explicit and positively meaningful' relationship. In this section, we shall treat these two labels synonymously. In Sect. 4.2. however, we subject Schellenberg's explication of divine love as involving the seeking of an 'explicit and positively meaningful' relationship to closer scrutiny.

21 Schellenberg (personal correspondence, 7th July, 2006).

管 Springer
} 
an 'understanding' of something. On one interpretation (the one which Schellenberg seems to prefer), to understand something is to have a grasp of its essence. Yet it seems that understanding something cannot simply and exclusively be equated with having a grasp of its essence. This issue cannot be decided with a quick reference to ordinary language use in everyday English. Aside from the fact that the latter evolves, there are in fact a variety of examples that immediately complicate the notion of what it means to 'understand' something. A simple example will bring this out.

Consider a person who thinks that he has an understanding of what he takes to be the best of human love. It certainly seems plausible to suggest that this person can reasonably claim to understand the best in human love even though he refrains from claiming that he has latched on to its essence. For example, after having come across numerous instances of homosexual couples who seem to be in loving and committed relationships, this person might think that his understanding of the best of human love, which he thought could obtain only between heterosexual couples, is not essentially true. Such a person nevertheless has an understanding of human love.

These examples illustrate that there can be a logical gap between understanding something and having an insight into its essence; only the latter can allow us to infer a conclusion that is conceptually and necessarily true. So our original question remains: is our understanding of human love-even what we take to be the best in human love-something that is indeed conceptually and necessarily true? All that Schellenberg seems to have offered is the argument that our understanding of human love holds in all possible worlds (containing human beings) because we have an understanding of what is essential to human love. But this argument is hardly rationally persuasive, for it rests on a (synonymous) begging of the question - the premise is simply a reworded expression of the conclusion; put another way, no one who was already committed to the conclusion would question the premise. Thus, Schellenberg's response still gives us no substantive reason to think that P1 of the hiddenness argument is a conceptual truth. ${ }^{22}$

If essences, then, are not as readily available as Schellenberg seems to think, the question remains whether all possible worlds containing loving human beings will see them seeking personal (or explicit and positively meaningful) relationships Even in this world of ours, we can see how (some) human beings might be loving even though they do not seek a personal relationship with others. For example, a childless woman living in Auckland might be a sponsor of a young child growing up in Dhaka. Suppose that, over time, this woman comes to love the child (she continually receives updates on the child's well-being, her education, achievements, etc.) but she doesn't seek a personal relationship with her. Does this mean that the woman's love for the child is somehow not quite as 'worthy' of the title of 'love' as compared to those people who express love for the child through a personal relationship? ${ }^{23}$ We don't think it is clear that the answer here is an obvious, unequivocal 'yes'. Indeed, it is surely conceivable

22 The charge of question-begging becomes all the more apparent when one considers some of the examples Schellenberg uses to support his claim. See footnote below.

23 To begin with, one has to take note of the perspectival shifts that may animate this illustration throughout. Of course, the workings and plausibility of this analogy may depend on whether we focus on the perspective of the sponsor or recipient (surely, this is a matter of emphasis since none of the two parties can be left out altogether). All we are saying, however, is that it is not obvious that the child's lack of awareness of her sponsor's loving actions diminishes or lessens the quality of the sponsor's love. In saying this, we merely aim at preserving sufficient leeway in constructing and assessing any such analogical illustration. However, one may enforce the present worries about premature claims regarding 'cheapened' love by considering one of Schellenberg's own examples provided in his 
that the woman's love for her sponsor child might in fact be 'superior' (for lack of a better term) than those who love the child in a personal relationship. And, surely, if it is conceivable how, in this world, certain human beings might be loving even though they do not seek personal relationships, it is certainly conceivable that there are other possible worlds in which this is also the case. Thus, the claim that the seeking of a personal relationship is an essential part of human love (i.e. that it obtains in every possible world containing human beings) is extravagant and unsupported. Schellenberg is not unaware of such an objection to his claim that the conditional given in P1 is a conceptual truth. As he notes in the presentation of the hiddenness argument in Divine Hiddenness,

[I]t will at some points in the argument be necessary to appeal to features of the actual world which we cannot assume are replicated in every possible world containing human beings. ${ }^{24}$

If this is correct, then Schellenberg cannot claim that his initial conditional premise, $\mathrm{P} 1$, is a conceptual truth. If our considerations over human love may not hold in every possible world containing human beings, and if it is by reference to human love that we form our conception of divine love, then we cannot be sure that our conception of divine love is applicable in every possible world in which humans exist; in other words, we cannot be sure that our conception of divine love is necessarily true.

For this reason, we think that Schellenberg's attempt to support P1 as a conceptual truth, one which is also necessarily true and known a priori, is a failure. But Schellenberg has another strand of argumentation based on analogy which he uses to support P1. Let us now turn to that.

\footnotetext{
Footnote 23 continued

'What the Hiddenness of God Reveals: A Collaborative Discussion' (see pp. 47-48). In one of his most daring and patently unconvincing examples, Schellenberg envisages an ex-convict mother "just coming out of jail ... whose child, unaware that his biological mother is alive, is relating wonderfully to a newly acquired step-mother". In such a situation, it seems plausible to think that, "not needing his whole world to be turned upside down by this rather large new piece of information", the ex-convict mother should refrain from seeking personal relationship with her child. Or, at the very least, this possibility should remain as a live option. However, Schellenberg will have none of this. In response, he says that "love itself ... by definition involves seeking personal relationship" and so the ex-convict mother - if she truly loves her child - "would not remove herself from the life of the beloved or fail to appear in it in the first place just because some incompatible good as great as or even greater than personal interaction with herself over that period of time happens to present itself" (emphasis ours). We think that Schellenberg's argument here is committing the self-sealing fallacy by simply defining love as entailing the seeking of personal relationship. It begs the question by effectively insulating personal interaction, as the defining quality of love, from any critical comparison with other traits that may relevantly contribute to the nature of love. Indeed, Schellenberg's claim that the ex-convict mother should seek personal relationship with her child even if there is "some incompatible good as great as or even greater than personal interaction" strikes these authors as highly implausible. Schellenberg himself does not seem altogether comfortable with the featuring of this illustration; for he concedes that "there is a sense in which such examples are just not relevant to our understanding of God's love, since the goodness, the contribution to our well-being, represented by the possibility of choosing to become personally related to God, even for a time, is so very great" (emphasis ours). This claim, it should be noted, is not relevant to the present point that it is not obvious that the seeking of personal relationship is an essential part of human love, illustrated by our example of the loving sponsor of the child in Dhaka.

24 Schellenberg, Divine Hiddenness, p. 8. Emphasis ours.

Springer
} 


\subsubsection{Varnished Vanstone: critiquing Schellenberg's analogy argument}

In Divine Hiddenness and Human Reason, Schellenberg's interest lies mainly with the role of evidence in belief formation and it is therefore not surprising that he devotes less space to discussing and grounding the notion of love, which will take centre stage in the hiddenness argument's later format. Even so, it is quite perplexing to find that, in his early discussion of 'Some Epistemic Implications of Divine Love', ${ }^{25}$ he rests content mostly with a single quote in passing from William Hubert Vanstone's book, Love's Endeavour, Love's Expense:

If I love you ... I must also make it possible for you to draw on me personally - ... I wish to make available to you the resources of an intimate personal relationship with me. This, indeed, is part of what is involved in self-giving. As W.H. Vanstone puts it, "the authenticity of love must imply a totality of giving - that which we call the giving of self or self-giving. The self is the totality of what a man has and is: and it is no less than this that is offered or made available in love." 26

Against the odds, however, this inconspicuous reference proves quite devastating to Schellenberg's overall argument, not only as far as its initial rendering is concerned but particularly with respect to its subsequent, love-centred formulation. ${ }^{27}$ Upon scrutiny, Vanstone's position fits neither version of the hiddenness argument. What is more, not only does the view propounded in Love's Endeavor, Love's Expense not lend itself to be enlisted for Schellenberg's early as well as later groundwork for his atheistic conclusion, it can effectively be turned against both deliveries of the hiddenness argument. Thus Vanstone, and the authors whom he overtly draws from, emerge not just as uneasy allies but as powerful philosophico-theological opponents of Schellenberg's atheistic venture.

To be clear, then, our purpose is not simply to defend Vanstone against a clear misappropriation through Schellenberg's selective quotation. In other words, the following criticism wouldn't lose any of its relevance and force were it the case that Schellenberg himself had not referred to Vanstone at all. Schellenberg's own reference is just an oddity, while our philosophical interest lies, of course, with Vanstone's actual arguments which, as it turns out, can be used against Schellenberg's position, and any other similar view. Especially with the recent version of Schellenberg's hiddenness argument in mind, the orientation of our criticism is more on the offence. Focused on the comparative method for devising arguments from analogy, concerned with the key traits of human love vis-à-vis divine love, we argue that Vanstone's position provides several powerful undercutting defeaters against Schellenberg's analogical argument in support of P1. These defeaters relate to the following three main characteristics of Vanstone's view: what he describes as his 'phenomenological method' for determining the "analogue" of "God's love" (69), ${ }^{28}$ his significant modification of the most common attributes of what John Bishop calls "omniGod" (i.e. a personal Deity characterized by omnipotence, omniscience, omnibenevolence) (Bishop,

\footnotetext{
25 See Divine Hiddenness, Ch. 1.

26 Vanstone (1977, p. 45). Schellenberg references this book in Divine Hiddenness, p. 18, footnote 4.

27 For the initial rendering of the hiddenness argument, see Schellenberg's Divine Hiddenness. What we refer to as the subsequent, love-centred version can be found in, for example, his 'Does Divine Hiddenness Justify Atheism?'
}

28 All page numbers for Vanstone refer to: Love's Endeavor, Love's Expense. 
1998), with particular emphasis on God's vulnerability qua Creator; and his criterion for recognition of divine love.

Turning to the first item on our list of the aforementioned three key features of his theological platform, Vanstone introduces the methodological framework for his entire book in phenomenological terms: "It may be", he says, "that we have never met, in human experience, perfectly authentic love. Nevertheless we may extrapolate, from the distortions which are rejected, the form which authentic love must take ... When we give an account of the authentic by detecting a pattern in that which is rejected as mere appearance, then our method may properly be described as phenomenological: ..." (p. 41). In short, Vanstone's phenomenological method works ex negativo. Even if we could never experience directly the positive side of authentic love, still we could get at its meaning through a phenomenological detour. For humans, as Vanstone says, are equipped with what he calls a "practical power of discrimination" (p. 42), which allows them to recognise the positive through the negative. Such practical discrimination works "as if, by examining a number of broken and variously distorted bones, one should describe a complete and perfect skeleton" (p. 41).

In this vein, God's love is characterised as 'total self-giving', as expressed in the first quotation above, which Schellenberg selected for inclusion in his first book. However, what Schellenberg forgets to mention in this place is that Vanstone's notion of selfgiving is embedded in a particular theory of kenosis, which interprets total self-giving as total self-emptying. Along these lines, Vanstone's inquiry into the nature of love is expressly focused on the relation between Creator and creation, and here his main finding is that God unreservedly gives Himself over to His creation, without holding anything back. Hence, for Vanstone, 'love's expense' or cost (as announced in the title of his book) is epitomised by God's vulnerability as inevitably engendered by the activity of creation.

If God is love, and if the universe is His creation, then for the being of the universe God is totally expended in precarious endeavour, of which the issue, as triumph or as tragedy, has passed from His hands. For that issue, as triumphant or tragic, God waits upon the response of His creation. He waits as the artist or as the lover waits, having given all. (p. 74)

This brings us to the second item on our list of the three most prominent traits of Vanstone's view, since this passage raises several claims that fly in the face of traditional omniGod theism, which should have given Schellenberg pause in importing Vanstone's conception of love. To begin with, the loving richness of a creation-in-progress is bought at the cost of God's utter exhaustion in the act of creation, resulting in a state of permanent Divine vulnerability as His creation keeps unfolding. Out of self-giving love for His creation-to-be, He has forfeited control over earthly future affairs, in that "triumph or ... tragedy has passed from His hands". This directly gainsays God's attribute of omnipotence. At the same time, the future trajectory of tragedy or triumph is not predictable by God either, which might undercut the attribute of omniscience. Last but not least, the traditional meaning of God's omnibenevolence is significantly modified, insofar as it is reduced to something that is perhaps not incompatible with authentic love but clearly distinct from it. Put in Vanstone's brusque terms, "kindness or benevolence ... under its own name is usually welcome: but it becomes an affront when it masquerades as love" (p. 42). ${ }^{29}$ While their respective take on benevolence

${ }^{29}$ Cf. also his prior remarks made in the context of introducing the first 'phenomenological parameter' of limitation: "It may be noticed in passing that pretences and parodies of love are not only recognised: 
as different from genuine love appears largely congruent, Schellenberg's overarching strategy of turning traditional claims of theism against the theist position itself, can hardly accommodate for Vanstone's express abandonment of the traditional conceptions of God's omnipotence and omniscience.

Still within the specific context of Schellenberg's analogical argument in support of P1, the glaring discrepancies between the two authors can be brought into even sharper relief, with respect to Vanstone's central featuring of art or artistic activity as the analogical paradigm for the creativity of love. As quoted above, God "waits as the artist or as the lover waits, having given all" (p. 74). Two of the basic constituents of Vanstone's understanding of Divine self-giving love are thus completely absent from Schellenberg's truncated, borrowed version thereof: a detailed exploration of the idea of God as artist and the suggestion that upon His precarious endeavour in the course of an on-going and open-ended process of creation, it is in fact God who is waiting for a response by His creatures, rather than His creatures waiting for sufficient evidence that would preclude non-resistant nonbelief among them.

Hence, following Vanstone more thoroughly would put a rather different spin on Schellenberg's analogical miniature narratives, presented in his 2004 debate with Moser on the question "Does Divine Hiddenness Justify Atheism?" In the last piece of a triptych of ever more grave short stories, Schellenberg asks his readers to put themselves in the position of an abandoned amnestic child, waking up into the life-threatening reality of vast rain forest. Of course, you don't remember being accompanied by your mother into this jungle, "but in your moments of deepest pain and misery you call for her anyway," and you do so "for days and days ... but with no response" until finally a jaguar catches you off guard, silencing your cries forever (2004, p. 31). The child in this story, as in the other two, represents the kind of sincere seeker of the Divine whose general profile has previously been intimated, at least in part, by Schellenberg's earlier reference to the Pascalian mindset. ${ }^{30}$ This kind of mindset is genuinely open to an encounter with the Divine but not graced with any confirmation that would sustain the minimum of belief necessary for entering into an explicit and positively meaningful relationship with God. Schellenberg's atheistic conclusion rejects Pascal's solution to this despair-inspiring situation, of course, but it is Pascal's notion of honest and whole-hearted seeking from which Schellenberg's argument receives much of its sting. As the children of God, if there was one, we are in "serious need of divine help" (Ibid., p. 33), and yet our cries like that of the amnestic child in the jungle are not heard. Thus Schellenberg infers that there is no God, for "[a] loving mother would not be hidden from her child in circumstances like those mentioned if

Footnote 29 continued

they are also resented. What a man will accept when it is presented under its true colours will be an affront when it is disguised as love. Most people are willing, and even glad, to be of use to other people; and are ready to make their skill or knowledge available to another who seeks help or counsel. But when the benefit of their skill or knowledge is obtained under the masquerade of love or the guise of friendship there is immediate and just resentment", pp. 40-41.

30 In Divine Hiddenness, p. 141, one of Schellenberg's crucial quotations is from Pascal's Pensées, Fragment 429: This is what I see and what troubles me. I look around in every direction and all I see is darkness. Nature has nothing to offer me that does not give rise to doubt and anxiety. If I saw no sign there of a Divinity I should decide on a negative solution: if I saw signs of a Creator everywhere I should peacefully settle down in the faith. But, seeing too much to deny and not enough to affirm, I am in a pitiful state, ... in the state in which I am, not knowing what I am or what I ought to do, I know neither my condition nor my duty. My whole heart strains to know what the true good is in order to pursue it: no price would be too high to pay for eternity. 
she could help it". (Ibid., p. 32) "But if omnipotence means anything", Schellenberg continues, "it means that God couldn't ever be prevented from responding to the cries of God's human children. The disanalogy we see here", he holds, "far from weakening the argument that starts out from the analogy, permits us to complete it". (Ibid., p. 34)

Vanstone's account, as should be clear by now, points in a very different direction. In direct opposition to what appears to be a claim about unlimited interventionist powers on the part of Schellenberg, he insists not only on the possibility but on the inevitability of the fact that God as Creator cannot at all times predict, respond to, and prevent the tragedies in our lives. Crucially, such inevitability must not be mistaken for conceptual necessity. For, with Vanstone, such limitations pertain to the general problem of concrete creative activity, which applies to God just as to any other artist.

[The artist] is faced with the problem of working within a self-chosen form; and the solution to the problem must be worked out in the creative process. The problem arises not because the artist has chosen the 'wrong' form but because he has chosen some kind of form - because he has chosen not merely to express himself but to do so in some kind of determinate way. This problem is present in all creativity, in every process of imparting oneself to that which is truly other than oneself: one must 'find the way' in which, through risk and failure and the redemption of failure, the other may be able to receive. (p. 64)

Accordingly, such limitations cannot be derived from the concept of God, but can only be ascertained a posteriori from the perspective of the sincere seeker and possible theist who finds herself within an on-going process of what will then be interpreted as a work of God's self-giving and self-emptying love. Because of his robust notion of omnipotence, Schellenberg, in his jungle story, never entertains the more cooperative possibility that God might be the vulnerable one who is waiting for a response from His creation.

This omission also puts in question the more specific traits of the child-status of the abandoned sincere seeker. In none of the three stories does Schellenberg specify the age of the child, which seems fair game given the built-in generality of any such analogy. Yet, especially in the rain forest version, the reader is arguably lured into associating the image of a toddler or a child that is only a few years old. But what if the 'child' was a teenager, ${ }^{31}$ perhaps similar to 'Francine'32 after she has matured into possessing all the necessary cognitive and affective equipment for a relationship with God. If so, the child might be a bit more mobile than Schellenberg's story suggests. Surely frightened and very timidly, she might still explore the surroundings of the spot in which she woke up, and-God knows - upon doing so she might happen upon a woman in a perilous pond "fending off a crocodile" (Schellenberg's image, again). Here it doesn't matter whether you are amnestic or not. The woman is a stranger, but you may still join forces and overcome this reptile together or die trying. This joint effort of survival and the personal bonds that may grow out of it, surely makes for an 'explicit and positively meaningful' relationship (life-changing, life-enhancing, or

31 The point we are making here is that it all depends on the kind of analogy for which one is opting. This concern was raised already in the introduction to Divine Hiddenness: New Essays. As Howard-Snyder and Moser write, "Different expectations may be motivated by different analogies", p. 7.

32 For the specifics of the 'Francine' character, see Divine Hiddenness, pp. 49-50.

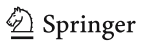


life-ending experience), despite the fact that you don't recognise this woman as your long-lost mother or, via analogy, God. ${ }^{33}$

We have thus arrived at the last of the three main characteristics of Vanstone's view, which shows the implausibility of Schellenberg's depicting him as a fellow-spokesman for authentic love - the issue of recognition. For Vanstone, unreserved self-giving comes at the price of vulnerability and implies doing away with what he perceives as false supremacy conceptions of God's powers, prevalent among contemporary theologians and the corresponding aberrations of popular theist devotion. Thus, Vanstone is at his most emphatic when he militates against trivialising (cf. p. 61) the activity of creation, as if it was "serene and effortless" and, "one might say, "of the left hand of God"' (p. 60). "Supremacy", he writes, "is not the relationship of the artist to the work of art, nor of the lover to the object of His love... That God should be superior, in every or any respect [!], to an inferior universe is a quite illegitimate deduction from the doctrine of creation. It is also a deduction which endangers the integrity of religion. For it tends to reduce religion to the prudent recognition of divine supremacy; ..." (p. 61).

This last reference to prudentialist reduction is rather unfortunate, for it would seem to render Vanstone's point irrelevant to Schellenberg's project. After all, Schellenberg (1993, pp. 21-23) has repeatedly pointed out that his conception of divine love implies a God who would not value the relationship to His creatures only in terms of the benefits that His children might reap from it, but also for the relationship's own sake, i.e., its intrinsic value. Importantly, Vanstone's present point cuts deeper than prudentialism and thus cannot be easily deflected along the lines of this familiar counter-argument by Schellenberg. For Vanstone's main point about God's loving creativity and our human recognition thereof, we take it, relates to the nature of religious experience, in general, and its temporal structure, in particular. This also goes to show that Vanstone is not as theologically crude as we might have made him out to be up to this point, when highlighting his own recurrent stress on divine vulnerability. Apropos recognition or personal knowability, Vanstone thus anticipates an incisive objection to his analogy argument, namely the suggestion he might have pushed the inevitable aspect of anthropomorphism way too far:

The activity of God in creation must be vulnerable. It would be more natural to say that, in His activity, God Himself must be vulnerable, but in saying this there would be a danger of introducing an excess of anthropomorphism into our reflection on the love of God (p. 66).

We know only that God is love. We know only the activity of God. We know that God is vulnerable only in the sense in which the activity of love may be said to be vulnerable (p. 67).

\footnotetext{
33 Schellenberg (2004) might reject this last illustration. He does consider the possibility of the loving mother being distracted through her own share of perils encountered in the rain forest, like a crocodile (p. 32) or some similarly dangerous creature. Yet, in the end he insists that if "omnipotence" and "divine resourcefulness" (p. 34) carry any weight in the traditional theistic sense, then such "distraction' cannot occur or factor decisively. Consequently, it would mean pushing the analogy too far, if we were to depict the incognito God as seriously in danger and in need of human (our imagined teenager's) help. However, the notion of 'total self-giving', as imported by Schellenberg, was situated in a Vanstonean framework where God is vulnerable. Hence it is incumbent upon Schellenberg to show how the Vanstonean notion of total self-giving could be maintained within a scheme of omniGod theism, contra Vanstone's determined gesture of distancing himself from traditional theology. Until such compatibility is demonstrated, Schellenberg's analogical argument in support of P1 appears to rest on an inconclusive oil-and-water composition.
} 
What is important to note is the actual scope of this comment on knowability. Within the Vanstonean kenotic framework of self-giving love, it is not only God's vulnerability that can be known only mediately, namely through the concrete manifestations of His creative activity, the same applies to His general power of loving His creatures as well. Here we are, again, at the very core of Vanstone's argument, expressed in his fundamental claim that "God is love" (emphasis ours). When it comes to the enabling conditions as well as the limits for us humans to recognise God as the loving God we are referred to His loving works, within the course of an on-going creation over which He has not complete control. God does not exist serenely and supremely over and above the tragic-triumphant to and fro of His creation but has fully emptied or submerged into it. In other words, God can never be a 'static object' (or, at any rate, inactive object) of our religious experience, however 'nonsensory' 34 it may be. But this implies that actual recognition of God's love is never 'momentary', i.e., it can never be encapsulated within a single revelatory timeslice of divine presence. ${ }^{35}$

On this point, then, Schellenberg and Vanstone part ways most decisively, and as far as we are concerned, Vanstone is the one who comes out swinging. The crux is that Schellenberg relies on the possibility of a basic, revelatory encounter between the personal human and the personal divine, ${ }^{36}$ whereas Vanstone, overtly indebted to Paul Tillich's Cultural Protestantism, ${ }^{37}$ holds that any such encounter can be only indirect, namely, mediated through concrete (artistic, symbolic) expressions of love.

In light not only of the incompatible but strongly undermining features of Vanstone's non-traditionalist conception of a vulnerable God's authentic, self-giving love, over against Schellenberg's leaning toward a supreme and omnipotent image of God, we consider Schellenberg's analogical argument in support of P1 as unsuccessful. Independent of whether or not one agrees with Vanstone's conception of God on its own terms, Schellenberg's reliance on a Vanstone-inspired notion of divine love has proven distorted in character. Moreover, Vanstone's own argument from analogy, when properly considered within its context of Tillich-style Christology, provides powerful reasons to reject Schellenberg's notion of recognition, which mainly relies on the idea of a basic, revelatory encounter with the personal divine as opposed to indirect, temporally patterned experiences of God's love through His creative works. Even if encounters of the former kind are in principle possible, Schellenberg has not shown how they could be properly construed as displaying the love-defining quality of care and guidance $e^{38}$ which, it seems to us, is much better explained in terms of revelation as a patterned process.

\footnotetext{
34 For "nonsensory" see Divine Hiddenness, p. 49.

35 Interestingly, in a very similar context, William Alston shies away from definitively judging or discarding Tillich's objection to thinking of God as a particular "object" of experience. See Alston (1991, pp. 30-31); particularly footnote 18 .

36 See Schellenberg 2005b, p.300, as quoted earlier.

37 Throughout his book, Vanstone shows himself as a declared follower of the theological thought associated with the names of Paul Tillich and Reinhold Niebuhr (for Tillich and Niebuhr, see: p. 7; for Tillich, in particular, see: xix; cf. also p. 59 on Tillich-style supra-evidentialism; and pp. 106-107 on proper Christian-symbol use and its "risk"). In light of Vanstone's own remarks on 'Christology' (p. 58) and 'Trinitarian theology' (pp. 68-69), this also invokes the Christological thought of F.W.J. Schelling (1775-1854), whom Tillich never failed to acknowledge as one of the primary, if not the primary, philosophical inspiration of his thinking.
}

38 For 'divine guidance', see Divine Hiddenness, p. 49.

基 Springer 
4.2 Is the belief that God exists a necessary condition to be in a position to exercise one's capacity for relationship with God?

The second premise of the expectations sub-argument (and of the overall hiddenness argument), P2, states that the belief that God exists is a necessary condition to be in a position to participate in an explicit and positively meaningful relationship with God. Schellenberg's clearest elaboration and defence of this claim can be found in the following passage from Divine Hiddenness:

[A] personal relationship with God entails belief in Divine existence, that is, entails a disposition to "feel it true" that God exists. This claim seems obviously true. For I cannot love God, be grateful to God, or contemplate God's goodness unless I believe that there is a God. An adequate description of such attitudes and actions entails reference to belief in propositions such as the following: "God is the source of my being"; "God loves me"; "God is to be praised." And clearly, one can only believe propositions such as these if one believes that God exists. It is important to note that my point here is a logical one. There is something logically amiss in the suggestion that I could display attitudes and perform actions of the sort in question without being disposed to feel it true that God exists. It is not as though someone who cannot be grateful to God or praise God because she does not believe there is a God could do so if only she tried a little harder. Such attitudes and actions are not just contingently difficult but logically impossible for one who does not believe that God exists. ${ }^{39}$

Before we evaluate Schellenberg's central claim here, it is necessary to clarify what exactly in the personal relationship with God belief is logically required for. As we shall see shortly, trying to understand the sort of relationship Schellenberg is interested in is by no means a straightforward task.

The "personal relationship with God" that Schellenberg speaks of in this quote is elsewhere described in his book as an explicit and reciprocal one. ${ }^{40}$ In his more recent work, however, he drops the term 'reciprocal' and opts for the adjectival phrase 'positively meaningful' instead. "I have always intended 'positively meaningful", he says, "but that notion is perhaps not entailed by 'reciprocal', so now I mention it explicitly". ${ }^{41}$ We are not sure what Schellenberg means by a 'positively meaningful' relationship with God, since he never states precisely what that description of it refers to.

Positive meaningfulness is not synonymous with (mere) reciprocity, for, if it were, Schellenberg's substitution of the latter by the former would be superfluous. Nor is it the same as explicitness, since Schellenberg clearly distinguishes this characteristic from positive meaningfulness. Nor is positive meaningfulness the same as intimacy. To see this, consider the following remarks from Schellenberg:

[W]e need not concede that belief of a certain (presumably quite high) degree of strength is necessary for personal relationship with God. Even a weak belief that God exists is compatible with gratefulness, love toward God, trust, contemplation, and the like, for even a weak belief involves a disposition to feel it true

39 Schellenberg, Divine Hiddenness, p. 30.

40 Ibid., p. 18.

41 Schellenberg, personal correspondence (6th September, 2005). 
that [God exists]. If I feel, however weakly, that it is true that there is a God, I may be moved to praise him and to struggle with him in prayer in ways that would be ruled out were I to, for example, be uncertain whether [God exists]. ${ }^{42}$

In his discussion of the above passage, Robert McKim takes Schellenberg to be suggesting that "the difference between strong and weak belief would be reflected in different prospects for personal relationships", and that "an intimate personal relationship would require something more than weak belief". (Mckim, 2001, p.102) But if, as Schellenberg admits, one can be personally related to God while weakly believing that God exists, then one can be personally related to God non-intimately (for intimacy will require "something more than weak belief" as McKim says). Thus, intimacy is not an integral part of a personal relationship with God. Since Schellenberg wishes to define a personal relationship with God with reference to 'explicitness' and 'positive meaningfulness', a conceptual elaboration of these terms cannot include intimacy.

If positive meaningfulness isn't the same as (mere) reciprocity, explicitness, or intimacy, what, then, does it refer to? Perhaps what Schellenberg has in mind is that a positively meaningful relationship with God involves a certain kind of reciprocity. To bring out this interpretation of positive meaningfulness, consider Paul K. Moser's response to Schellenberg's claim that the belief that there is a God is logically required to hear God speaking to you:

Schellenberg claims that "it is logically impossible for you to hear God speak to you ... while not believing that there is a God". This is false. It rests on a confusion of (a) hearing God and (b) hearing God as (interpreted as) God. We have no reason whatever to think that (a) requires (b). Likewise, ordinary hearing of a human person does not require hearing that person as (interpreted as) that person. One can hear a voice, for instance, without (correctly) identifying the source of that voice. So people may actually hear God through conscience without correctly identifying the "voice" of conscience as God. (Moser, 2004, p. 58)

In a similar vein, William J. Wainwright (2002, p. 113) suggests that "[w]hen the nonbeliever responds to the good she sees, she may ... be responding to God Himself". Schellenberg, however, is not satisfied with this sort of reply. In response to Wainwright's remark here, he says that Wainwright has substituted his own notion of relationship between God and human beings for Schellenberg's conception of it which involves "explicit, reciprocal interaction". (2005a, p. 208) And since what Moser says bears resemblance to Wainwright's proposal, presumably Schellenberg will level the same charge against Moser as well.

But it is not at all clear to us that in the examples given by Wainwright and Moser there is either a lack of explicitness or reciprocity. Suppose I am an atheist, and God speaks to me clearly through my conscience so that, when faced with a moral decision, I have no hesitations about the proper course of action; I then 'respond' to the voice of God in a firm and committed way, e.g. in ending up doing the right thing, even though I do not believe that God exists. This state of affairs is certainly conceivable. And it is also conceivable in a way where my acting in accordance with the good is, as Wainwright (2002, p. 114) proposes, more or less extensionally equivalent to acting on theistic belief even though I do not hold the belief that there is a God. "Then the righteous will answer him and say, 'Lord, when did we see you hungry and feed you, or

42 Schellenberg, Divine Hiddenness, p. 32.
Springer 
thirsty and give you drink? When did we see you a stranger and welcome you, or naked and clothe you? When did we see you ill or in prison, and visit you?' And the king will say to them in reply, 'Amen, I say to you, whatever you did for one of these least brothers of mine, you did for me"'. (Matthew 25:37-40). So in the scenarios described by Wainwright and Moser, it appears coherent to suppose that one can engage in both an explicit and reciprocal relationship with God without believing that God exists.

Still, perhaps Schellenberg might grant here that, although it might be possible to acquire both explicitness and reciprocity in a relationship with God without believing that there is a God, such a relationship is not 'positively meaningful' because - and here is where our interpretation comes in - the reciprocity is not predicated on regarding it true that there is a God. Perhaps there is something tragic or absurd about being in a relationship with God without regarding it true that the other party (God) exists. We believe this to be, at best, a moot point, but will not contest it here. Rather, we shall suppose for the sake of argument that a positively meaningful relationship with God requires reciprocity based on one regarding it true that there is a God.

Tidying up Schellenberg's claim in this manner renders the objections by Moser and Wainwright irrelevant. For, even if it is possible to have an explicit and reciprocal relationship with God in the ways described by both Moser and Wainwright without believing that God exists, it does not appear possible to have an explicit and positively meaningful relationship (in the sense we have just described) without having the belief that there is a God.

Thus, we now come to an assessment of Schellenberg's central claim: the belief that God exists is a necessary condition for an explicit and positively meaningful relationship with God, where the positively meaningful part of the relationship refers (on our interpretation) to a reciprocal relationship based on a person regarding it true that there is a God. Even with this clarification, which renders Schellenberg's claim impervious to the criticisms of Moser and Wainwright, we maintain that Schellenberg's claim is false. To begin with, we have already seen how both explicitness and reciprocity can obtain for a person in a relationship with God even though she does not believe that God exists. Schellenberg's claim can be narrowed down, therefore, to the claim that the belief that God exists is a necessary condition for regarding it true that there is a God, as a constitutive part of being in a relationship with Him. This is false for the following reasons.

All that is required is some sort of (positive) attitude towards the proposition ' $\mathrm{God}$ exists'. This propositional attitude may or may not be doxastic. It is true that people tend to think that the heart of theistic faith rests on beliefs about God, but a number of philosophers of religion, such as Richard Swinburne (1981, pp. 115-117), Louis Pojman $(1986,2003)$ and William Alston (1996), have explored the possibility of faith without belief. According to Swinburne (1981, p. 116), it is possible to be a person of faith on purely pragmatic grounds by acting on the assumption that God exists. The man of pragmatist faith, says Swinburne, "prays for his bretheren [sic], not necessarily because he believes that there is a God who hears his prayers, but because only if there is can the world be set right". (Ibid., p. 117) Pojman has argued that, in circumstances where one thinks that the evidence for God's existence is insufficient, the propositional attitude of hope can serve as an adequate substitute for belief where one of the characteristics of hope is a "desire for the state of affairs in question to obtain or the proposition to be true". (1986, p. 162; 2003, p. 544) And, for Alston, one can accept that God exists rather than believe that He does, and indeed that "accepting basic Christian doctrines can undergird a full-blown Christian commitment". (1996, p. 9) 
Due to restrictions of space, we will only consider Alston's suggestion that acceptance can suffice for an authentic commitment to God. The main factor that distinguishes belief from acceptance, says Alston, is that if I believe that $p$ then I feel it to be the case that $p$ whereas accepting that $p$ "will definitely not include a tendency to feel that $p$ if the question of whether $p$ arises". (1996, p. 9) But accepting that $p$ is not synonymous with merely acting on the assumption that $p$, for the former involves a "more positive attitude" towards $p$ which the latter need not have. (Ibid., p. 11) We hold that a person can engage in an explicit and positively meaningful relationship with God (in the sense we have just elaborated) while accepting (and not believing) that there is a God. As Alston writes,

In view of the concentration on belief in the thought about religion, it is important to realize that the person who accepts the doctrines is not necessarily inferior to the believer in commitment to the Christian life, or in the seriousness, faithfulness, or intensity with which she pursues it. The accepter may pray just as faithfully, worship God just as regularly, strive as earnestly to follow the way of life enjoined on us by Christ, look as pervasively on interpersonal relationships, vocation, and social issues through the lens of the Christian faith. (1996, p. 17)

So acceptance makes it possible to enter into a relationship with God that is explicit, reciprocal and predicated on a (non-doxastic) propositional attitude towards the claim that there is a God (i.e. a positively meaningful relationship). For this, we do not need the belief that God exists. We conclude, therefore, that the second premise of the expectations sub-argument, $\mathrm{P} 2$, is false.

The possibility of substituting belief by the propositional attitude of acceptance may seem trivial at this stage. However, as we will show in the next section, this substitution poses some interesting challenges to the prospect of formulating alternative versions of the hiddenness argument. Such prospects will have to be considered because the present version of the hiddenness argument is unsuccessful.

\section{Future prospects for variants of hiddenness arguments}

We have argued that both the conceptual and analogical considerations given by Schellenberg to support his crucial conditional claim, viz. that the existence of a perfectly loving God entails (or strongly suggests) a certain state of affairs, are contestable; that is, Schellenberg's arguments do not show that the existence of a perfectly loving God implies that all non-resisting creatures capable of an explicit and positively meaningful relationship with God are in a position to participate in such a relationship. We have also argued that, even if Schellenberg is correct in thinking that such a relationship does follow given what we know about God, one can, in fact, be in a position to participate in an explicit and positively meaningful relationship with God without possessing the belief that God exists, e.g. through the propositional attitude of acceptance. Each of these two (independent) criticisms suffices to render the hiddenness argument unsuccessful.

As we noted earlier, however, Schellenberg's hiddenness argument is one among several variants of arguments from divine hiddenness. Might it not be possible, therefore, to formulate a version of the argument that is immune to our criticisms? Certainly, we do not wish to deny the possibility that this can be done. But what we wish to point out now is that any such formulation faces a number of obstacles.

笔 Springer 
Since the conceptual and analogical featuring of P1 is blocked in light of our previous criticisms, the burden is upon the proponent of the varied or modified hiddenness argument to pursue another route of defence that is broadly empirical but not susceptible to the same objections as Schellenberg's own analogical argument. It is important to note that we are not claiming that $\mathrm{P} 1$ is false; rather, we are simply pointing out that, thus far, the justification for it is inadequate. Hence, a theist can rationally remain sceptical about whether or not a perfectly loving God would remain hidden, unless evidence is provided to the contrary.

Another significant hindrance to variants of the hiddenness argument arises when we consider that the belief that God exists is not necessary in order to be in a position to participate in an explicit and positively meaningful relationship with God. As we have argued, a number of alternative propositional attitudes can be maintained without belief and, significantly, some of these attitudes are under our direct control. In Divine Hiddenness, the sting of Schellenberg's argument comes from his emphasis on the reasonable non-believer. This type of person is someone who is open and sympathetic to theistic belief, but is unable, upon adequate investigation, to form the belief that God exists because of insufficient evidence. Since it is typically evidence that results in belief formation, and since the evidence is lacking in the case of theistic belief, the reasonable non-believer cannot acquire the belief that God exists - a necessary condition to pursue a relationship with God. Within Schellenberg's evidentialist account of belief formation, then, the reasonable non-believer thus faces a logical impediment to his sincere and prolonged efforts which seems dramatically unfair.

This rather serious charge, however, dissipates when we consider the fact that belief is not necessarily required to enter into the sort of relationship with God that Schellenberg is interested in. Rather, one can accept God's existence and consequently enter into a relationship with Him. Moreover, one can do so voluntarily because, as Alston maintains, acceptance is a mental act that one can freely perform. On this understanding, acceptance remains possible even when the relevant evidence is insufficient (for belief formation). This point is crucial in that the reasonable non-believer cannot be construed to be in a state of abandonment or futile search as originally dramatised by Schellenberg, since sincere seekers of this sort can now choose to accept God's existence in the absence of evidentially grounded belief. Given that reasonable nonbelievers may enter into a relationship with God based on acceptance, a proponent interested in defending a variation of the hiddenness argument might follow Schellenberg's recent shift to the class of non-resistant nonbelievers (recall that the former was a sub-class of the latter).

There are certain people who fall into the category of non-resistant nonbelievers but are outside the class of reasonable nonbelievers. Consider a primitive Amazonian tribe whose members have not so much as even heard of 'God' - the 'prevangelical populace' as we might call them. Though such people have the affective cognitive equipment to enter into a relationship with God, they are not in a position to exercise this capacity because none of the various propositional attitudes we have looked at, such as belief, hope or acceptance is available to them. They simply haven't been exposed to the conception of a theistic God, much less a perfectly loving one. And so our remarks on the possibility of acceptance as an adequate substitute for belief will not work in their case.

In response to this objection, one can point out that P1 in Schellenberg's argument has yet to be supported. If this particular premise is incorporated into variants of the hiddenness argument, it still needs to be corroborated by good reasons for 
thinking that a perfectly loving God would want to relate to everyone, including the Amazonians. Still, consider two further replies. For one thing, this situation seems to be more focused on the issue of divine justice as opposed to divine love. The 'prevangelics' appear unjustly barred not from the resources but from the conditions for properly exercising their affective cognitive equipment. But Schellenberg himself appears to provide some good suggestions for responding to a construal of the problem in terms of divine justice:

[I]f only God's justice need be saved, the theist may always point to the possibility that everything will even out in the end - that those who fail to benefit from belief in this life will be compensated hereafter. Or else she may claim that it is not unjust to give a gift to someone while not giving it to others, unless everyone can be shown to be entitled to it. ${ }^{43}$

For another thing, the theist may now appeal to 'epistemic limitation' or possible 'goods of mystery' as McKim calls them. (2001, pp. 114-117). For all we know, it might be that the non-universality of propositional attitudes towards God is related to the existence of some unknown (greater) goods. Interestingly, Schellenberg (2005b, pp. 299-301) thinks that the appeal to such goods, as made by McKim, is questionbegging. In a critical passage, he writes:

[C]arefully phrased, this claim tells us that such unknown reasons are not ruled out by anything we know or justifiably believe, but this assumes that belief of the conditional premise that has been our focus in this essay is unjustified instead of showing it; for if belief of that premise is justified, then there is something we are justified in believing that rules out unknown reasons of the sort in question - namely that premise! The central point to take note of here is that the truth of the conditional 'If God exists, then there is no reasonable non-belief' is a sufficient condition for the absence of any reason for God to permit reasonable non-belief, since if there were such a reason, God might freely choose to act on it, and so the unequivocal claim of the conditional would be false. Hence, if we are justified in believing the premise in question, and recognize this point, we are also justified in believing that there are no reasons, known or unknown, for God to permit reasonable non-belief. (Ibid., pp. 300-301)

What is important for assessing this passage is that Schellenberg is banking on his justification for the conditional premise to block any appeal to possible goods of mystery. If, however, that justification is undermined - as we have shown in our paper-then, for all we know, there might exist such goods even though they are beyond our ken. ${ }^{44}$ Even if one is not satisfied with selective 'gift-giving' as a just practice by a perfectly loving God, then this lingering impression of injustice can be countered by an appeal to possible goods of mystery.

43 Schellenberg, Divine Hiddenness, p. 4, footnote 3.

44 It is very important to avoid confusion here between rebutting and undercutting Schellenberg's argument against possible goods of mystery. Let $c$ represent justified belief in Schellenberg's conditional claim (if God exists, there is no non-resistant nonbelief) and let $g$ represent goods of mystery for the sake of which God permits non-resistant nonbelief. Now, Schellenberg's argument against possible goods of mystery is a straightforward modus ponens: (1) If $c$ then not-g; (2) $c$; therefore, (3) not-g. Our response to this argument is that the support for (2) is undermined. If so, then this argument against possible goods of mystery is unsound. Ergo, the appeal to possible goods of mystery for the sake of which God permits non-resistant nonbelief is still a viable option for the theist. 


\section{Conclusion}

In our paper, we have looked at the latest rendition of Schellenberg's hiddenness argument, and argued that it is unsuccessful in light of the failure of its core-the expectations sub-argument. Of the latter, we have seen that its first premise can be seriously contested because no good reasons were given - either by way of conceptual or analogical considerations - for thinking that a perfectly loving God would relate to us all (i.e. the support for the first premise can be undercut). The second premise is false because the belief that God exists is not logically required in order to relate to Him (i.e. the support for the second premise can be rebutted). Turning to possible variants of the argument, we observed that the necessary modifications that follow from our criticisms leave them with much less of a sting than the original. We also explained why formulating any such variants will prove to be difficult. ${ }^{45}$

\section{References}

Alston, W. (1991). Perceiving God: The epistemology of religious experience. Ithaca: Cornell University Press.

Alston, W. P. (1996). Belief, acceptance, and religious faith. In J. Jordan \& D. Howard-Snyder (Eds.), Faith, freedom and rationality (pp. 3-27). Rowman \& Littlefield.

Bishop, J. (1998). Can there be alternative concepts of god? Noûs, 32(2), 174-188.

Howard-Snyder, D. \& Moser, P. K. (Eds.). (2002). Divine hiddenness: New essays. Cambridge University Press.

Howard-Snyder, D. \& Moser, P. K. (2002). Introduction: Divine hiddenness. In D. Howard-Snyder \& P. K. Moser (Eds.), Divine hiddenness: New essays (p. 7). Cambridge University Press.

McKim, R. (2001). Religious ambiguity and religious diversity. Oxford University Press.

Moser, P. (Ed.). (1987). A priori knowledge. Oxford: Oxford University Press.

Moser, P. (2004). Reply to Schellenberg. In M. L. Peterson \& R. J. Van Arragon (Eds.), Contemporary debates in the philosophy of religion. Blackwell.

Pojman, L. (1986). Faith without belief? Faith and Philosophy, 3(2), 157-176.

Pojman, L. (2003). Faith, doubt and hope or does faith entail belief? In R. Gale \& A. R. Pruss (Eds.), The existence of God (pp. 535-547). Ashgate.

Pollock, J. (1986). Contemporary theories of knowledge. New Jersey: Rowman and Littlefield.

Schellenberg, J. L. (1993). Divine hiddenness and human reason. Ithaca: Cornell University Press.

Schellenberg, J. L. (2002). What the hiddenness of God reveals: A collaborative discussion. In D. Howard-Snyder \& P. K. Moser (Eds.), Divine hiddenness: New essays (p. 57). Cambridge University Press.

Schellenberg, J. L. (2004). Does divine hiddenness justify atheism? In M. L. Peterson \& R. J. Van Arragon (Eds.), Contemporary debates in the philosophy of religion (pp. 30-41). Blackwell.

Schellenberg, J. L. (2005a). The hiddenness argument revisited (I). Religious Studies, 41, 201-215.

Schellenberg, J. L. (2005b). The hiddenness argument revisited (II). Religious Studies, 41, 287-303.

Swinburne R. (1981). Faith and reason. Oxford: Clarendon Press.

Swinburne, R. (1987). Analyticity, necessity and apriority. In P. Moser (Ed.), A priori knowledge. Oxford: Oxford University Press.

Vanstone, W. H. (1977). Love's endeavor, love's expense. London: Darton, Longman and Todd.

Wainwright, W. J. (2002). Jonathan Edwards and the hiddenness of God. In D. Howard-Snyder \& P. K. Moser (Eds.), Divine hiddenness: New essays. Cambridge: Cambridge University Press.

45 We would like to thank Zain Ali, John Bishop, Kathleen Higgins, Fred Kroon, Jonathan McKeown-Green and Nick Trakakis for helpful discussions on the hiddenness argument. We are also very grateful to J.L. Schellenberg for his correspondence and feedback regarding our paper. Finally, we wish to thank our audience at the 2005 Annual Conference of the New Zealand Division of the Australasian Association of Philosophy held at Otago University where an earlier version of this paper was presented. 